\title{
ANATOMIA DA MADEIRA DE DUAS ESPÉCIES DE BACCHARIS, NATIVAS NO RIO GRANDE DO SUL ${ }^{1}$
}

\author{
SIDINEI RODRIGUES DOS SANTOS 2 JOSÉ NEWTON CARDOSO MARCHIORI ${ }^{3}$ \\ ANELISE MARTA SIEGLOCH ${ }^{4}$ ANABELA SILVEIRA DE OLIVEIRA-DEBLE ${ }^{5}$
}

\section{RESUMO}

São anatomicamente descritas e ilustradas as madeiras de Baccharis cognata DC. e Baccharis uncinella DC., com base em material procedente do Rio Grande do Sul. As principais características observadas correspondem ao descrito na literatura para o gênero Baccharis e tribo Astereae: porosidade difusa; poros não solitários, muito numerosos $\left(>100 \mathrm{~mm}^{2}\right)$ e de pequeno diâmetro $(<50 \mu \mathrm{m})$; elementos vasculares curtos $(<350 \mu \mathrm{m})$; placas de perfuração simples; vasos com espessamentos espiralados; pontoações intervasculares pequenas $(<7 \mu \mathrm{m})$ e alternas; pontoações raio-vasculares semelhantes às intervasculares; parênquima paratraqueal fusiforme e seriado; fibras libriformes curtas $(<750 \mu \mathrm{m})$, não-septadas; e presença de cristais. As principais diferenças entre as duas espécies residem na presença ou não de estratificação no parênquima axial, bem como na largura e composição de raios, e no arranjo de poros.

Palavras-chave: Anatomia da madeira, Baccharis, Asteraceae, Astereae.

\section{ABSTRACT}

[Wood anatomy of two Baccharis species from Rio Grande do Sul state, Brazil].

The woods of Baccharis cognata DC. and Baccharis uncinella DC. are presently described, based on samples from Rio Grande do Sul state, Brazil. The most important features agree with literature references to genus Baccharis and tribe Astereae: diffuse porosity; very numerous pores $\left(>100 \mathrm{~mm}^{2}\right)$, in multiples $(<50 \mu \mathrm{m}$ of diameter); short vessel elements $(<350 \mu \mathrm{m})$; simple perforation plates; vessels with spiral thickenings; alternate intervessel pits $(<7 \mu \mathrm{m})$; vessel-ray pits similar to intervessel pits; libriform, non-septate fibres $(<750 \mu \mathrm{m})$; and presence of crystals. The species segregation can be realized by the presence of storied parenchyma, as well as the width and cellular composition of rays, and the pattern of pores.

Key words: Asteraceae, Astereae, Baccharis, Wood anatomy.

\section{INTRODUÇÃO}

De taxonomia complexa, o gênero Baccharis L. compreende cerca de 360 espécies de ervas perenes, subarbustos, arbustos e pequenas árvores, distribuídas desde o Canadá até o extremo sul da Argentina e Chile (Schneider, 2009).

1 Recebido para publicação em 10-4-2012 e aceito para publicação em 15-5-2012.

2 Biólogo, Dr. Laboratório de Anatomia da Madeira, Departamento de Ciências Florestais, Universidade Federal de Santa Maria. Santa Maria, RS, Brasil. sthurt.bio@gmail.com

3 Engenheiro Florestal, Dr. Bolsista de Produtividade em Pesquisa $(\mathrm{CNPq}-$ Brasil). Professor Titular do Departamento de Ciências Florestais, UFSM.

4 Engenheira Florestal, bolsista (Capes). Mestranda do Programa de Pós-Graduação em Engenharia Florestal, UFSM.

5 Bióloga, Dra. Professora da Urcamp (Universidade da Região da Campanha), Dom Pedrito, Rio Grande do Sul.
Por vezes, a abundância de algumas espécies chega a impor-se na fisionomia da vegetação, caso dos chamados "vassourais". No Brasil, de acordo com Oliveira et al. (2006), encontramse, aproximadamente, 146 espécies do gênero; o Rio Grande do Sul, com 94 espécies nativas, é um dos estados mais bem representados (Deble \& Oliveira, 2011), neste sentido.

A delimitação em Baccharis é considerada difícil, tanto pelo polimorfismo e caráter dióico da maioria das espécies, como pelo grande número de binômios descritos com superficialidade, constantes na literatura (Oliveira et al, 2006). Por conseqüência, a abrangência do gênero e sua circunscrição na subtribo Baccharinae como um todo tem sido alvo de constantes alterações, como demonstram os trabalhos de Barroso (1976), Nesom (1994), Giuliano (2000, 
2001), Barroso \& Bueno (2002), Deble et al. (2004) e Oliveira et al. (2006). Atualmente, todos os gêneros americanos de Baccharinae (Baccharidastrum, Baccharidiopsis, Heterothalamulopsis e Heterothalamus) foram reduzidos à sinonímia de Baccharis (Müller, 2006), com exceção de Archibaccharis; cabe ressaltar-se, todavia, que esta interpretação não goza de unanimidade entre os especialistas (Deble \& Oliveira, 2011).

Nativa no Uruguai, Argentina, Paraguai e Brasil, de Pernambuco ao Rio Grande do Sul (Oliveira-Deble, 2008), Baccharis cognata DC. é subarbusto ereto de 0,30 a $1 \mathrm{~m}$ de altura, folhoso até o ápice, com folhas obovais (8-30 x 5-15 mm), opostas, subopostas ou alternas, sésseis, glabras, trinervadas, denteadas na metade superior, obtusas no ápice e atenuadas na base. Sob o ponto de vista taxonômico, a espécie vincula-se à seção Cylindricae Heering e Série Cylindricae (Heering) Giuliano (Oliveira \& Marchiori, 2006).

Nativa em campos de altitude, do Rio de Janeiro e São Paulo ao Rio Grande do Sul (Oliveira-Deble, 2008), Baccharis uncinella DC. é arbusto de folhas sésseis, obovais ou elípticas (6-15 x 4-6 mm), uninérvias, de margens revolutas, com ápice obtuso-mucronulado e face inferior cinéreo-tomentosa. Sob o ponto de vista taxonômico, a espécie pertence à seção Racemosae Ariza, juntamente com Baccharis dracundulifolia DC., entre outras "vassouras".

A descrição anatômica de Baccharis cognata DC. e Baccharis uncinella DC., objeto do presente estudo, dá continuidade a uma série de publicações sobre madeiras sul-rio-grandenses de Asteraceae e visa a ampliar o conhecimento estrutural da tribo Baccharinae.

\section{REVISÃO DA LITERATURA}

O pequeno porte dos indivíduos, aspecto que limita a utilização da madeira, justifica a escassa literatura anatômica sobre o gênero Baccharis.
Para a tribo Astereae, Carlquist (1960) refere poros de diâmetro inferior a $50 \mu \mathrm{m}$ para a maioria das espécies, podendo ultrapassar 100 $\mu \mathrm{m}$ em alguns Baccharis; o comprimento de elementos vasculares, geralmente inferior a 150 $\mu \mathrm{m}$, poucas vezes ultrapassa a $300 \mu \mathrm{m}$. A presença de traqueídeos vasculares foi anotada apenas para nove espécies de Baccharis; os espessamentos espiralados, por sua vez, podem ou não ocorrer no gênero em estudo. Placas de perfuração escalariformes não ocorrem na tribo, com exceção de uma espécie de Grindelia e cristais prismáticos são raros, inclusive em espécies de Baccharis. $\mathrm{O}$ arranjo de vasos é caráter muito variável em Astereae: em Baccharis thesioides e $B$. viminea, por exemplo, os poros de lenho inicial são maiores e dispostos em grupos menos numerosos, diferentemente do lenho tardio, com seus vasos de menor diâmetro, dispostos em agrupamentos extremamente numerosos; nas demais espécies, os grandes agrupamentos distribuem-se por todo o xilema. Poros em racemos são referidos para Baccharis angustifolia e agrupamentos tangenciais para $B$. rosmarinifolia. Grandes agregados de vasos, em zig-zag ou em arranjo diagonal, são mencionados para espécies de Baccharis e de Olearia.

Em sua descrição da família, Metcalfe \& Chalk (1972) relacionam para algumas espécies de Baccharis: vasos muito pequenos $(<50$ $\mu \mathrm{m}$ ), em padrão nitidamente radial, oblíquo ou em linhas tangenciais; porosidade em anel ou semidifusa; elementos vasculares com espessamentos espiralados, em espécies de regiões temperadas; e parênquima axial com numerosas células fusiformes, por vezes estratificado.

Para a subtribo Baccharinae, a qual pertence o gênero em análise, são referidos os seguintes caracteres anatômicos: porosidade difusa; poros de pequeno diâmetro $(<50 \mu \mathrm{m})$; elementos vasculares curtos $(<300 \mu \mathrm{m})$; placas de perfuração simples; pontoações intervasculares alternas; parênquima paratraqueal; raios heterogêneos; fibras libriformes curtas $(<750 \mu \mathrm{m})$, 
não-septadas; bem como a ausência de espessamentos espiralados e presença de cristais, em algumas espécies (Marchiori \& Oliveira-Deble, 2007).

Além da literatura acima comentada, cabe salientar as contribuições anatômicas de Marchiori \& Oliveira-Deble (2007) e Marchiori et al. (2007) sobre espécies sul-rio-grandenses de Baccharis, bem como de Oliveira \& Marchiori (2005) e Oliveira et al. (2005a,b), para outros gêneros de Baccharinae. Mais numerosas são as publicações de enfoque medicinal sobre espécies de Baccharis (Marinho, 1996; Cortadi et al., 1999; Pereira \& Oliveira, 1996; Budel et al., 2003, 2004a, 2004b).

\section{MATERIAL E MÉTODOS}

O material estudado consiste de duas amostras de madeira, que foram coletadas especialmente para o presente trabalho e anexadas à Xiloteca do Departamento de Ciências Florestais (HDCF) da Universidade Federal de Santa Maria, com os seguintes registros:

- Baccharis cognata DC. Bagé, BR 153, beira da estrada, $20 \mathrm{~km}$ do Arroio Passo da Areia, subarbusto $70 \mathrm{~cm}$; L.P. Deble \& A.S. de Oliveira, 24-IV-2005 (MBM).

- Baccharis uncinella DC. São José dos Ausentes, Serra da Rocinha, 6-XI-2004, L.P. Deble \& A.S. de Oliveira-Deble (MBM).

Para a confecção das lâminas histológicas foram extraídos três corpos de prova da parte mais externa do lenho de cada uma das amostras, próxima ao câmbio, orientados para obtenção de cortes nos três planos anatômicos; um quarto bloquinho foi também retirado, com vistas à maceração.

A confecção das lâminas histológicas seguiu a metodologia descrita em Burger \& Richter (1991). Para a maceração, seguiu-se o método de Franklin, modificado (Kraus \& Arduin, 1997). Os cortes anatômicos foram tingidos com safra-blau; o macerado, apenas com safranina (1\%). A montagem das lâminas permanentes foi feita com Entellan.

A descrição baseou-se nas recomendações do IAWA Committee (1989). A frequiência de poros foi obtida de forma indireta, a partir de um quadrado de área conhecida superposto a fotomicrografias de seções transversais da madeira.

As medições foram realizadas em microscópio Carl Zeiss, no Laboratório de Anatomia da Madeira da Universidade Federal de Santa Maria. Nas características quantitativas, os números entre parênteses equivalem aos valores mínimos e máximos observados; o valor que acompanha a média é o desvio padrão. As fotomicrografias foram tomadas em microscópio Olympus CX40, equipado com câmera digital Olympus Camedia c3000, no Laboratório de Anatomia da Madeira da Universidade Federal do Paraná, a quem os autores agradecem.

\section{DESCRIÇÕES ANATÔMICAS \\ Baccharis cognata DC.}

Anéis de crescimento: demarcados, fracamente, pelo estreitamento radial e/ou maior espessura da parede de fibras no lenho tardio. Porosidade difusa.

Vasos: poligonais, solitários e, principalmente, em múltiplos radiais e racemiformes, compondo, em conjunto, um arranjo dendrítico pouco pronunciado. Vasos com $24 \pm 7(12,5-42,5)$ $\mu \mathrm{m}$ de diâmetro e freqüência superior a 100 poros $/ \mathrm{mm}^{2}$ (242 \pm 63,8 (169 - 319). Elementos vasculares estratificados em plano radial; de 196 $\pm 29,6(150-270) \mu \mathrm{m}$ de comprimento, com placas de perfuração simples, oblíquas, e tênues espessamentos espiralados na parede. Apêndices ausentes ou curtos, em apenas uma das extremidades, sobretudo nos vasos de maior diâmetro; nos de menor diâmetro, observam-se apêndices em ambas as extremidades e as placas de perfuração tendem a verticais. Pontoações intervasculares alternas, pequenas e circulares $(4,5 \pm 0,42(4,1-5,1) \mu \mathrm{m})$, com abertura inclusa. Pontoações raio-vasculares com aréolas dis- 

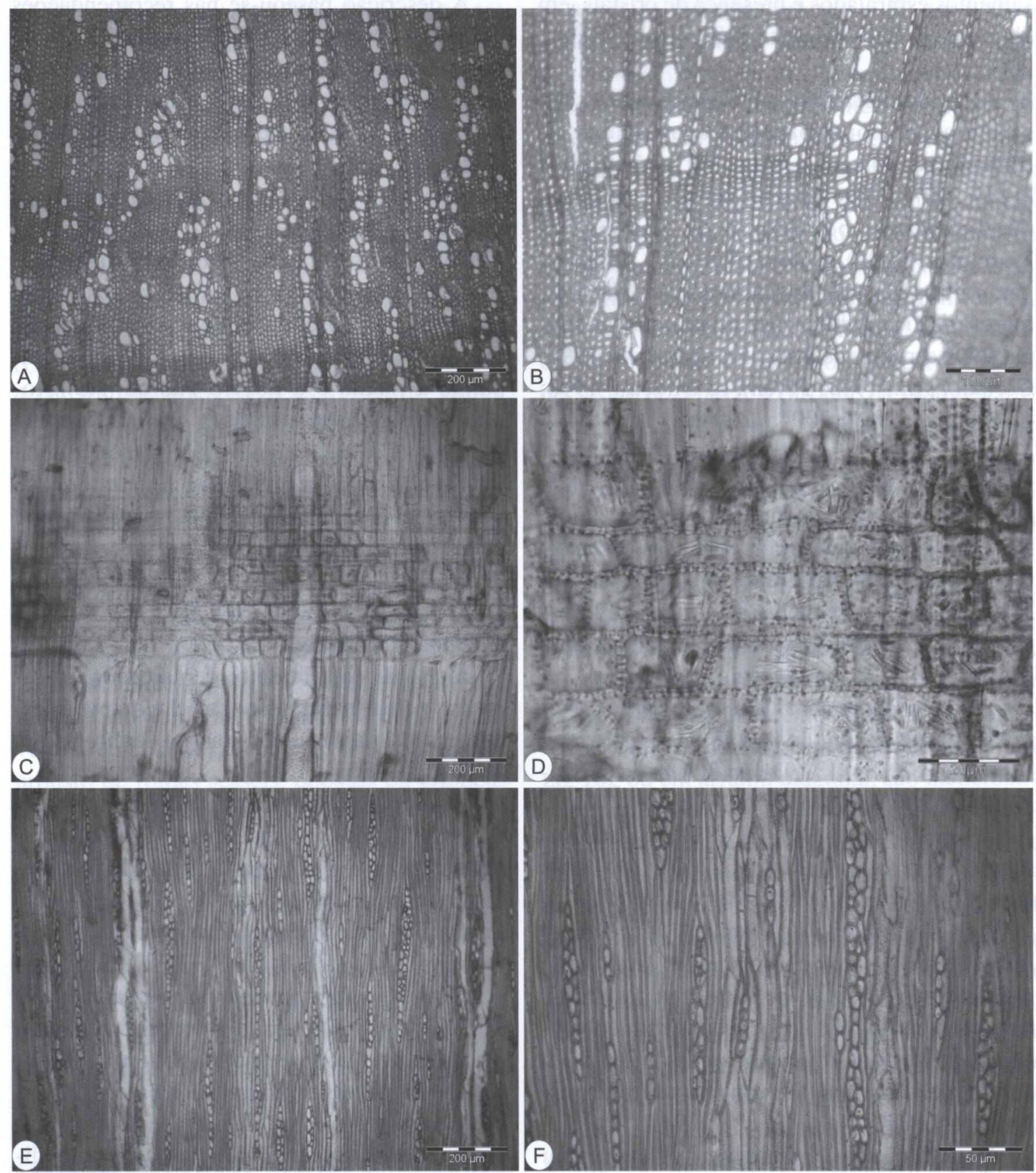

FIGURA 1 - Fotomicrografias da madeira de Baccharis cognata. A - Porosidade difusa, poros em múltiplos radiais e racemiformes, sem arranjo dendrítico (seção transversal). B - Fibras de paredes finas a espessas, achatadas no limite do anel de crescimento, e parênquima paratraqueal escasso (seção transversal). C - Parênquima paratraqueal e raio heterogêneo, com células procumbentes e quadradas (seção longitudinal radial). D - Detalhe de raio, com abundantes cristais aciculares; notar, igualmente, a presença de células de paredes disjuntas (seção longitudinal radial). E - Raios estreitos, com 1-3 células de largura, e vasos com placas oblíquas (seção longitudinal tangencial). F - Fibras não-septadas e parênquima axial fusiforme e seriado, com duas células por série (seção longitudinal tangencial). 
tintas, semelhantes às intervasculares, embora menores $(3,9 \pm 0,26(3,6-4,1) \mu \mathrm{m})$. Traqueídeos vasculares, presentes. Ornamentações e conteúdos, ausentes.

Parênquima axial: paratraqueal escasso, não estratificado, dos tipos fusiforme e seriado. Séries parenquimáticas de 2 células e $194 \pm 18,7$ (150 - 240) $\mu \mathrm{m}$ de altura. Células fusiformes de $164 \pm 31,7(120-230) \mu \mathrm{m}$ de comprimento.

Raios: com 1-3 células de largura e frequiência inferior a $12 / \mathrm{mm}(10 \pm 1,8(8-13)$. Raios uni e multisseriados, compostos de células procumbentes e quadradas. Os multisseriados, de $209 \pm 68,4(110-340) \mu \mathrm{m}$ e $10 \pm 3,4$ (5 - 19) células de altura; margens unisseriadas geralmente mais curtas do que o corpo central, com $1-6$ (9) células de altura. Os unisseriados, de $96 \pm 52,8(30-260) \mu \mathrm{m}$ e $4 \pm 2,6(1$ - 10) células de altura. Raios fusionados, freqüentes. Cristais aciculares, abundantes no tecido radial. Células perfuradas, células envolventes, estratificação e conteúdos, ausentes. Células radiais de paredes disjuntas, presentes.

Fibras: não-septadas, com pontoações simples ou inconspicuamente areoladas, principalmente nas faces radiais da parede; de $471 \pm 38,3$ (400 - 550) $\mu \mathrm{m}$ de comprimento e $15 \pm 1,3$ (12,5 - 17,5) $\mu \mathrm{m}$ de largura, com lúmen de $6,9 \pm 0,9$ $(5-8,7) \mu \mathrm{m}$ e paredes finas a espessas $(4,1 \pm$ $0,5(3,1-5) \mu \mathrm{m})$. Fibras gelatinosas, espessamentos espiralados e estratificação, ausentes.

Outros caracteres: variantes cambiais, tubos laticíferos e taniníferos, canais intercelulares, células oleíferas e células mucilaginosas, ausentes. Máculas medulares, presentes.

\section{Baccharis uncinella DC.}

Anéis de crescimento: distintos, delimitados pelo achatamento radial e/ou maior espessura e lignificação da parede de fibras no limite do anel. Porosidade difusa.

Vasos: em agrupamentos racemiformes de orientação radial, exceto nos anéis de crescimento mais internos, onde se observa padrão diagonal a dendrítico. Poros poligonais, com 23 \pm 5,8 $(15-37,5) \mu \mathrm{m}$ de diâmetro e freqüência superior a 100 poros $/ \mathrm{mm}^{2}(204 \pm 35(169-250)$. Elementos vasculares estratificados, de $206 \pm$ $25,5(160-250) \mu \mathrm{m}$ de comprimento, com placas de perfuração simples, geralmente oblíquas, e espessamentos espiralados na parede. Apêndices ausentes ou curtos, normalmente em uma das extremidades; nos vasos de menor diâmetro, observam-se apêndices em ambas as extremidades e placas de perfuração verticais. Pontoações intervasculares pequenas, circulares $(5,6 \pm 0,51(5,1-6,2) \mu \mathrm{m})$, alternas, com abertura inclusa. Pontoações raio-vasculares com bordas distintas, semelhantes às intervasculares, embora menores $(3,9 \pm 0,36(3,1$ - 4,1) $\mu \mathrm{m}$ ). Conteúdo abundante, no cerne. Traqueídeos vasculares e ornamentações, ausentes.

Parênquima axial: paratraqueal escasso, dos tipos fusiforme e seriado, estratificado. Séries parenquimáticas de $170 \pm 21,3(130-210) \mu \mathrm{m}$ de altura e 2 (raro mais) células. Células fusiformes de $162 \pm 19,8(110-200) \mu \mathrm{m}$ de comprimento.

Raios: com 1-4 células de largura e frequiência inferior a $12 / \mathrm{mm}(10 \pm 1,8(6-12)$. Raios uni e multisseriados, homocelulares, compostos inteiramente de células procumbentes, mais ou menos isodiamétricas e arredondadas em corte tangencial. Os multisseriados, predominantes, de $236 \pm 99(120-540) \mu \mathrm{m}$ e $14 \pm 6(6$ - 33) células de altura; margens unisseriadas mais curtas do que o corpo central, com $1-3$ (5) células. Os unisseriados, de $82 \pm 31,7$ (20 160) $\mu \mathrm{m}$ e $5 \pm 2,2(1-9)$ células de altura. Raios fusionados e células perfuradas, escassas. Cristais aciculares e conteúdos, abundantes, pelo menos em parte dos raios. Células envolventes e estratificação, ausentes.

Fibras: não-septadas, com pontoações simples ou inconspicuamente areoladas, dispostas, principalmente, nas faces radiais da parede; de $655 \pm 47,3(560-740) \mu \mathrm{m}$ de comprimento e $17,2 \pm 2,1(12,5-20) \mu m$ de largura, com lúmem de $8,5 \pm 1,8(5-10) \mu \mathrm{m}$ e paredes finas a espes- 
$\operatorname{sas}(4,3 \pm 0,82(2,5-6,2) \mu \mathrm{m})$. Fibras gelatinosas e espessamentos espiralados, ausentes.

Outros caracteres: variantes cambiais, tubos laticíferos e taniníferos, canais intercelulares, células oleíferas, células mucilaginosas e máculas medulares, ausentes.

\section{ANÁLISE DA ESTRUTURA ANATÔMICA}

As duas espécies em estudo compartilham diversas características anatômicas referidas para outras espécies do gênero, bem como para a maioria dos integrantes da subtribo Baccharinae e tribo Astereae, de acordo com Carlquist (1960), Metcalfe \& Chalk (1972) e Marchiori \& Oliveira-Deble (2007): porosidade difusa; poros não solitários de pequeno diâmetro $(<50 \mu \mathrm{m})$, muito numerosos $\left(>100 \mathrm{~mm}^{2}\right)$; elementos vasculares curtos $(<350 \mu \mathrm{m})$; placas de perfuração simples; espessamentos espiralados; pontoações intervasculares alternas, pequenas $(<7 \mu \mathrm{m})$; pontoações raio-vasculares semelhantes às intervasculares; raios uni e multisseriados; parênquima paratraqueal pouco abundante, dos tipos fusiforme e seriado; e fibras libriformes curtas $(<750 \mu \mathrm{m})$, nãoseptadas.

Entre os caracteres diferenciais, destaca-se, para Baccharis uncinella, a presença de raios homogêneos com até 4 células de largura e a estratificação do parênquima axial. De todas as Baccharinae descritas até o momento, somente Baccharis longoattenuata e Baccharis tridentata apresentam raios tão largos como os acima mencionados; raios homogêneos, por sua vez, não são citados na literatura para a mesma subtribo.

Com relação à estratificação do parênquima axial, o caráter consta, apenas, para Baccharis longoattenuata e Heterothalamus alienus, de acordo com a literatura. Apesar de não ser novidade, a presença de estratificação cresce em importância, por sua ocorrência restrita no gênero. Vale lembrar, ainda, que a observação destas duas características em Baccharis uncinella confere a esta madeira um grau evolutivo mais avançado, relativamente a Baccharis cognata e às demais espécies que carecem destes aspectos anatômicos, segundo Bailey (1953) e Kribs (1935).

Tanto Baccharis cognata como Baccharis uncinella apresentam cristais (aciculares) no tecido radial, aspecto que, embora incomum na família (Carlquist, 1960), foi também reportado por Marchiori \& Oliveira (2007) para Baccharis dracunculifolia (cristais aciculares) e Baccharis patens (cristais prismáticos). Por outro lado, Oliveira \& Marchiori (2005), Oliveira et al. (2005a,b) e Marchiori et al. (2007) não registraram a presença de cristais em outras madeiras de Baccharinae. Esta variabilidade recomenda o uso do caráter (presença/ausência/tipo de cristais) na separação de espécies da referida subtribo, sobretudo tendo-se em vista a notável homogeneidade estrutural do grupo (Marchiori \& Oliveira-Deble, 2007).

As duas espécies em estudo também podem ser separadas mediante o arranjo de poros. Baccharis cognata apresenta poros em múltiplos racemiformes pouco ramificados, compondo um fraco padrão dendrítico, semelhante ao referido por Marchiori et al. (2007) para Baccharis milleflora. Baccharis uncinella, por sua vez, distingue-se pelo típico padrão diagonal ou dendrítico (sobretudo nos anéis de crescimento mais internos), aspecto comum em Baccharinae, segundo Marchiori \& OliveiraDeble (2007).

Em ambas as madeiras investigadas, chama atenção o grande número de características anatômicas xeromórficas, tais como poros em múltiplos, elementos vasculares curtos e de pequeno diâmetro, vasos com espessamentos espiralados e fibras curtas. Na tribo Astereae (e gênero Baccharis), é freqüente a ocorrência de xeromorfismos (Carlquist, 1960, 1966; Marchiori \& Oliveira-Deble, 2007), inclusive na morfologia externa (hábito arbustivo, caules fotossintetizantes, folhas reduzidas, tricomas, xilopódios). Carlquist (1960, 1966), todavia, aventa a possibilidade de que este conjunto de 

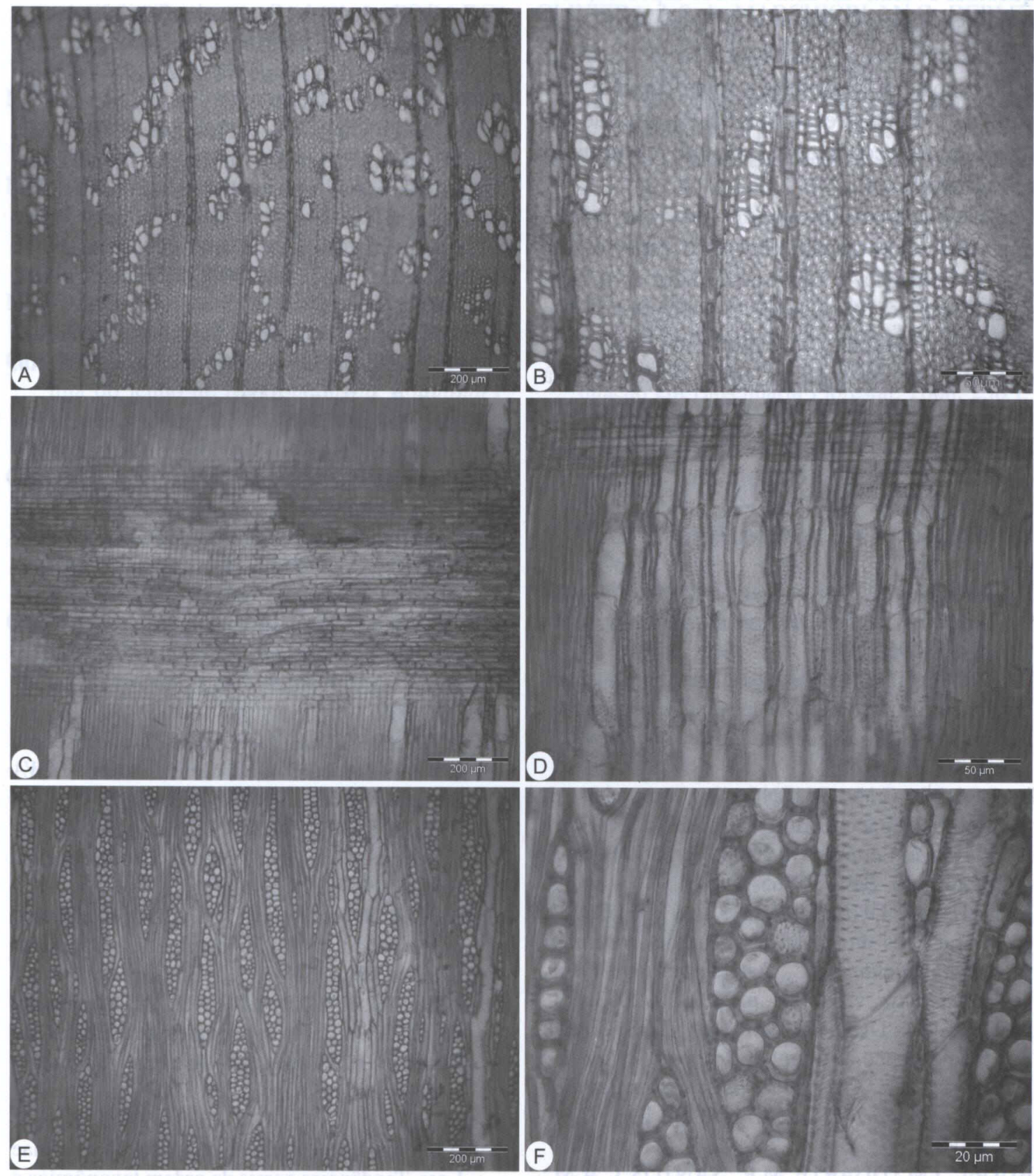

FIGURA 2 - Fotomicrografias da madeira de Baccharis uncinella. A - Vasos em arranjo diagonal ou dendrítico, com porosidade difusa (seção transversal). B - Fibras de paredes finas a espessas e parênquima paratraqueal escasso (seção transversal). C - Raio homogêneo, composto inteiramente de células procumbentes (seção longitudinal radial). D - Vasos estratificados, com placas de perfuração simples (seção longitudinal radial). E - Células radiais de seção arredondada, raios com até 4 células de largura, vasos estratificados e parênquima axial (seção longitudinal tangencial). F - Vasos com pontoações intervasculares alternas e espessamentos espiralados (seção longitudinal tangencial). 
caracteres, ou parte dele, esteja vinculado a questões evolutivas. Entre outros aspectos, este é o caso do comprimento de elementos vasculares, caráter que pode estar relacionado mais a uma posição filogenética relativamente elevada na tribo Astereae e família Asteraceae, do que a uma especialização adaptativa a ambientes xéricos.

O elevado número de características anatômicas compartilhadas pelas espécies em estudo confirma a homogeneidade estrutural salientada por Marchiori \& Oliveira-Deble (2007): em Baccharinae é mais fácil o reconhecimento de uma madeira como pertencente à subtribo como um todo, do que a um gênero em particular.

\section{REFERÊNCIAS BIBLIOGRÁFICAS}

BAILEY, I.W. Evolution of the tracheary tissue of land plants. American Journal of Botany, n. 40, p. 4-8, 1953.

BARROSO, G.M. Compositae, subtribo Baccharidinae Hoffman. Estudo das espécies ocorrentes no Brasil. Rodriguésia, Rio de Janeiro, v. 28, p. 3-273. 1976.

BARROSO, G.M.; BUENO, O. Compostas. 5. Subtribo: Baccharidinae. In: REITZ, R. Flora Ilustrada Catarinense. Itajaí: Herbário Barbosa Rodrigues, 2002. p. 765-1065.

BUDEL, J.M.; DUARTE, M.R.; SANTOS, C.A.M. Caracteres morfo-anatômicos de Baccharis gaudichaudiana DC., Asteraceae. Acta Farm. Bonaerense, v. 22, n. 4, p. 313-320, 2003.

BUDEL, J.M.; DUARTE, M.R.; SANTOS, C.A.M. Stem morpho-anatomy of Baccharis cylindrica (Less.) DC., Asteraceae. Revista Brasileira de Ciências Farmacêuticas, v. 40, n. 1, p. 93-99, 2004a.

BUDEL, J.M.; DUARTE, M.R.; SANTOS, C.A.M.; FARAGO, P.V. Morfoanatomia foliar e caulinar de Baccharis dracunculifolia DC., Asteraceae. Acta Farm. Bonaerense, v. 23, n. 4, p. 477-483, 2004b.

BURGER, L.M.; RICHTER, H.G. Anatomia da Madeira. São Paulo: Ed. Nobel, 1991. 154 p.

CARQUIST, S. Wood anatomy of Astereae
(Compositae). Tropical Woods, n. 113, p. 54-84, 1960.

CARQUIST, S. Wood anatomy of Compositae: a summary, with comments on factors controlling wood evolution. Aliso, v. 6, n. 2, p. 25-44, 1966.

CORTADI, A.; SAPIO, O.; Mc-CARGO, J.; SCANDIZZI, A.; GATTUSO, S.; GATTUSO, M. Anatomical studies of Baccharis articulata, Baccharis crispa and Baccharis trimera, "carquejas" used in folk medicine. Pharmaceutical Biology, v. 37, n. 5, p. 357-365, 1999.

DEBLE, L.P.; OLIVEIRA, A.S. de; MARCHIORI, J.N.C. Heterothalamulopsis, gênero novo da subtribo Baccharinae Lessing (AstereaeAsteraceae). Ciência Florestal, Santa Maria, v. 14, n. 1, p. 1-7, 2004.

DEBLE, L.P.; OLIVEIRA, A.S. de. Asteraceae Bercht. \& J. Presl (= Compositae Giseke) no Rio Grande do Sul. Ciência \& Ambiente, Santa Maria, n. 42, p. 93-112, 2011.

GIULIANO, D.A. Subtribo Baccharidinae. In: Hunziker, A. T. Flora Fanerogámica Argentina. Córdoba, 2000. v. 66. 73 p.

GIULIANO, D.A. Clasificación infragenérica de las espécies argentinas de Baccharis (Asteraceae, Astereae). Darwiniana, San Isidro, v. 39, p. 131154, 2001.

IAWA COMMITTEE. IAWA list of microscopic features for hardwood identification. IAWA Bulletin, v. 10, n. 3, p.218-359, 1989.

KRAUS, J.E.; ARDUIN, M. Manual básico de métodos em morfologia vegetal. Rio de Janeiro: EDUR, 1997. 198 p.

KRIBS, D.A. Salient lines of structural specialization in the wood rays of Dicotyledons. Botanical Gazette, 96, p. 547-557, 1935.

MARCHIORI, J.N.C.; OLIVEIRA, A.S. Anatomia da madeira de três espécies brasileiras de Baccharis L. (Asteraceae-Astereae). Balduinia, Santa Maria, n. 10, p. 1-10, 2007.

MARCHIORI, J.N.C.; OLIVEIRA-DEBLE, A.S. Anatomia da madeira na subtribo Baccharinae Less. Tendências gerais de ordem taxonômica e ecológica. Balduinia, Santa Maria, n. 11, p. 915, 2007.

MARCHIORI, J.N.C.; OLIVEIRA-DEBLE, A.S.; DENARDI, L. Anatomia da madeira de duas espécies brasileiras de Baccharis L. (Asteraceae - Astereae). Balduinia, Santa Maria, n. 11, p. 18, 2007. 
MARINHO, T,C. Anatomia e ultra-estrutura dos órgãos vegetativos de Baccharis pseudotenuifolia Teodoro e B. dracunculifolia DC. (Asteraceae). 1966. $101 \mathrm{f}$. Tese (Doutorado) USP, São Paulo, 1966.

METCALFE, C.R.; CHALK, L. Anatomy of the Dicotyledons. Oxford: Clarendon Press, 1972. $1500 \mathrm{p}$.

MÜLLER, J. Systematics of Baccharis (Compositae - Astereae) in Bolivia, including an overview of the genus. Systematics Botany Monographs, v. 76, p. 1-339, 2006.

NESOM, G. Subtribal classification of the Astereae (Asteraceae). Phytologia, v. 76, p. 193-274, 1994.

OLIVEIRA, A.S. de; MARCHIORI, J.N.C. Anatomia do lenho de Heterothalamus psiadioides Lessing (Asteraceae - Astereae). Balduinia, Santa Maria, n. 4, p. 20-24, 2005.

OLIVEIRA, A.S. de O.; MARCHIORI, J.N.C. Baccharis L. (Asteraceae - Astereae) no sul do Brasil. 1. Seção Cylindricae Heering, Série Cylindricae (Heering) Giuliano. Balduinia, Santa Maria, n. 7, p. 1-36, 2006.

OLIVEIRA, A.S. de; DEBLE, L.; MARCHIORI, J.N.C. Anatomia da madeira de duas espécies do gênero Heterothalamus Lessing (Asteraceae,
Astereae), nativas no Rio Grande do Sul. Ciência Florestal, v. 15, n. 1, p. 9-19, 2005a.

OLIVEIRA, A.S. de; MARCHIORI, J.N.C.; DEBLE, L. Anatomia do lenho de Heterothalamus wagenitzii (F. Hellw.) Deble, Oliveira \& Marchiori (Asteraceae - Astereae). Balduinia, Santa Maria, n. 2, p. 13-18, 2005 b.

OLIVEIRA, A.S. de; DEBLE, L.P.; SCHNEIDER, A.A.; MARCHIORI, J.N.C. Checklist do gênero Baccharis L. para o Brasil (AsteraceaeAstereae). Balduinia, n. 9, p. 17-27, 2006.

OLIVEIRA-DEBLE, A.S. de. Classificação infragenérica e atualizações nomenclaturais das espécies brasileiras de Baccharis L. (Asteraceae - Astereae). Santa Maria: Programa de Pós Graduação em Engenharia Florestal, 2008. 256 f. Tese (Doutorado em Engenharia Florestal).

PEREIRA, L.T.; OLIVEIRA, P.L. de. Anatomia do caule de Baccharis cylindrica (Less.) DC. (Asteraceae). Comun. Mus. Ciênc. Tecnol. PUCRS, Série Botânica, v. 2, n. 1, p. 29-48, 1996.

SCHNEIDER, A.A. Estudo taxonômico de Baccharis L. Sect. Caulopterae DC. (Asteraceae: Astereae) no Brasil. 2009. 197 f. Tese (Doutorado) UFRGS, Porto Alegre, 2009. 